\title{
Scale-specific correlations between habitat heterogeneity and soil fauna diversity along a landscape structure gradient
}

\author{
Adam J. Vanbergen · Allan D. Watt $\cdot$ Ruth Mitchell $\cdot$ \\ Anne-Marie Truscott $\cdot$ Stephen C. F. Palmer · Eva Ivits · \\ Paul Eggleton · T. Hefin Jones · José Paulo Sousa
}

Received: 14 August 2006 / Accepted: 2 May 2007 / Published online: 31 May 2007

(C) Springer-Verlag 2007

\begin{abstract}
Habitat heterogeneity contributes to the maintenance of diversity, but the extent that landscape-scale rather than local-scale heterogeneity influences the diversity of soil invertebrates - species with small range sizes-is less clear. Using a Scottish habitat heterogeneity gradient we correlated Collembola and lumbricid worm species richness and abundance with different elements (forest cover, habitat richness and patchiness) and qualities (plant species richness, soil variables) of habitat heterogeneity, at landscape $\left(1 \mathrm{~km}^{2}\right)$ and local (up to $200 \mathrm{~m}^{2}$ ) scales. Soil fauna assemblages showed considerable turnover in species composition
\end{abstract}

Communicated by Matthias Schaefer.

Electronic supplementary material The online version of this article (doi:10.1007/s00442-007-0766-3) contains supplementary material, which is available to authorized users.

A. J. Vanbergen $(\square) \cdot$ A. D. Watt · R. Mitchell · A.-M. Truscott S. C. F. Palmer

Centre for Ecology and Hydrology, Hill of Brathens,

Banchory, Aberdeenshire AB31 4BW, UK

e-mail: ajv@ceh.ac.uk

A. J. Vanbergen - T. H. Jones

Cardiff School of Biosciences, Cardiff University,

Cardiff CF10 3TL, UK

E. Ivits

Department of Remote Sensing and Land Information

Systems (FELIS), University of Freiburg, Freiburg, Germany

P. Eggleton

Soil Biodiversity Group, Department of Entomology,

The Natural History Museum, Cromwell Road,

London SW7 5BD, UK

J. P. Sousa

Institute of Environment and Life Sciences,

University of Coimbra, Coimbra, Portugal along this habitat heterogeneity gradient. Soil fauna species richness and turnover was greatest in landscapes that were a mosaic of habitats. Soil fauna diversity was hump-shaped along a gradient of forest cover, peaking where there was a mixture of forest and open habitats in the landscape. Landscape-scale habitat richness was positively correlated with lumbricid diversity, while Collembola and lumbricid abundances were negatively and positively related to landscape spatial patchiness. Furthermore, soil fauna diversity was positively correlated with plant diversity, which in turn peaked in the sites that were a mosaic of forest and open habitat patches. There was less evidence that local-scale habitat variables (habitat richness, tree cover, plant species richness, litter cover, soil $\mathrm{pH}$, depth of organic horizon) affected soil fauna diversity: Collembola diversity was independent of all these measures, while lumbricid diversity positively and negatively correlated with vascular plant species richness and tree canopy density. Landscape-scale habitat heterogeneity affects soil diversity regardless of taxon, while the influence of habitat heterogeneity at local scales is dependent on taxon identity, and hence ecological traits, e.g. body size. Landscape-scale habitat heterogeneity by providing different niches and refuges, together with passive dispersal and population patch dynamics, positively contributes to soil faunal diversity.

Keywords Biodiversity · Collembola $\cdot$ Earthworms · Plants $\cdot$ Remote-sensing $\cdot$ Spatial heterogeneity . Species diversity

\section{Introduction}

Habitat area and heterogeneity have a primary role in governing species diversity (MacArthur and Wilson 1967; 
Hanski 1999; Cam et al. 2002; Tscharntke et al. 2002; Benton et al. 2003). Anthropogenic forest fragmentation (Didham et al. 1998a; Davies et al. 2000; Andresen 2003), conversion to silviculture or agriculture (Eggleton et al. 2002; Dunn 2004) and land-use intensification (Lawton et al. 1998; Benton et al. 2003; Jones et al. 2003; Eggleton et al. 2005) alter the size and heterogeneity of habitats. These anthropogenic drivers can create landscapes that are a mosaic of habitats; these, in turn, can influence species diversity depending on how each species perceives this environmental heterogeneity (Tews et al. 2004). For example, spatial habitat heterogeneity may allow populations to persist by providing habitat refuges (Hanski 1999; Ellner et al. 2001); or lead to population declines and extinctions as a result of habitat loss or degradation (Didham et al. 1998b; Davies et al. 2000).

Taxonomic or functional identity is likely to be an important determinant of which habitat heterogeneity component (e.g. habitat area, patchiness, plant diversity) is relevant, and at which spatial scale (Roland and Taylor 1997; Steffan-Dewenter et al. 2002; Chust et al. 2004; Dauber et al. 2005). Furthermore, for a given taxon or species the response to habitat heterogeneity may be scale-specific. For example, carabid beetle assemblages have been shown to be positively influenced by habitat heterogeneity at microscales $\left(0.25 \mathrm{~m}^{2}\right)$ and mesoscales $\left(500-1,000 \mathrm{~m}^{2}\right)$ but not at macroscales (10 km) (Brose 2003; Tews et al. 2004); while in a separate study the loss of carabid species with landscape simplification varied according to trophic group (Purtauf et al. 2005). Differences in the response to habitat heterogeneity between taxa and at different scales arise largely as a consequence of the contrasting mobility, foraging or breeding requirements of the species in question (Ettema and Wardle 2002; Pearman 2002; Steffan-Dewenter et al. 2002; Thies et al. 2003). The importance of landscape-scale habitat heterogeneity for the diversity of actively mobile species (e.g. birds, bees, beetles) is well understood (Herrando and Brotons 2002; Steffan-Dewenter et al. 2002; Purtauf et al. 2005); and there is generally a positive relationship between habitat heterogeneity and landscape species richness (Tews et al. 2004). Comparatively little is known, however, about the impact of landscape-scale habitat heterogeneity on species, such as soil invertebrates, that operate at fine spatial scales (e.g. centimetres-metres) and are of restricted mobility (Chust et al. 2003; Dauber et al. 2005; Eggleton et al. 2005; Joschko et al. 2006).

One way in which terrestrial habitat heterogeneity affects the diversity of soil species assemblages is by producing variation in the structure and diversity of plant communities. Plot-scale experiments indicate that variation in plant diversity may affect soil invertebrate diversity; one possible mechanism, for example, is where an increase in plant litter diversity may facilitate soil species coexistence through either resource partitioning or increased physical niche space (Hansen 2000; Wardle et al. 2001; De Deyn et al. 2004; Bardgett et al. 2005). Such changes to plant and litter diversity may arise from patterns in land use and-in interaction with topography and geology - contribute to abiotic gradients (e.g. pH, moisture) that also shape the diversity of soil invertebrate assemblages (Ettema and Wardle 2002; Dauber et al. 2005; Eggleton et al. 2005; Joschko et al. 2006). Simple correlations, however, between above- and belowground diversity tend to be uncommon, idiosyncratic or weak (Hooper et al. 2000; Wardle et al. 2003); and often it is the identity and dominance, not diversity, of plant species that is important in driving soil fauna diversity (Ettema and Wardle 2002; Wardle et al. 2003; De Deyn et al. 2004).

Earlier studies of the influence of land use on Scottish soil macrofauna (Eggleton et al. 2005) and pan-European Collembola diversity (Sousa et al. 2006) indicate that habitat size, quality, heterogeneity and land-use type are important in shaping soil fauna diversity. We studied with a Scottish habitat heterogeneity gradient, at landscape $\left(1 \mathrm{~km}^{2}\right)$ and local (sampling point-up to $200 \mathrm{~m}^{2}$ ) spatial scales, the influence of different aspects of habitat heterogeneity-classified into "elements" (forest percentage cover, habitat richness and patchiness) or "qualities" (plant functional group diversity, litter cover, soil variables) based on Tews et al. (2004) —on the species richness and abundance of two functionally dissimilar soil taxa (Collembola and lumbricid worms). Collembola are primarily fungal grazers dependent on the presence of a plant detritus food web common to forests and extensive grassland, while lumbricids consume organic matter directly-and hence are less dependent on soil microbes - and the majority of lumbricid species are intolerant of acidic forest soils (Hopkin 1997; Bardgett and Cook 1998; Bardgett et al. 2005; Salamon et al. 2006). Thus, it is possible that the diversity of these two taxa will be sensitive to different qualities (e.g. litter cover, soil $\mathrm{pH}$ ) of the habitat heterogeneity gradient; while overall the diversity of both taxa may increase in response to increased habitat richness or habitat patchiness in the landscape because of the existence of additional niches and refuges (Hanski 1999; Ettema and Wardle 2002; Benton et al. 2003; Tews et al. 2004; Bardgett et al. 2005).

First, we assessed whether species turnover was great enough between the landscapes that comprise our habitat heterogeneity gradient to produce compositionally distinct Collembola and lumbricid worm assemblages. Second, at local and landscape scales we tested the influence of the different habitat "elements" and "qualities" on soil fauna diversity with the following hypotheses: (1) species richness, abundance and species turnover of both soil taxa would peak at the point of greatest habitat richness (number of different habitat types) and patchiness (number of habitat 
patches irrespective of type and size); (2) soil taxon identity determines which qualities of the habitat gradient influence diversity, with the predictions that (a) Collembola species richness and abundance is positively related to tree species richness while lumbricids positively relate to forb species richness, and (b) richness and abundance of Collembola and lumbricids are negatively and positively related to increasing soil $\mathrm{pH}$ and decreasing litter and organic matter content as the proportion of agricultural habitat increases.

\section{Methods}

Landscape-scale habitat heterogeneity gradient

Six landscape units (LUs) representing a gradient of habitat heterogeneity were established in Aberdeenshire, Scotland. Each LU was located in the River Dee catchment, no more than $10 \mathrm{~km}$ away from neighbouring sites (Table 1), enabling a comparison of landscape composition without a major geographical bias. Each LU was represented by a $1 \mathrm{~km} \times 1 \mathrm{~km}$ landscape square visually selected according to a predefined set of criteria corresponding to the predominant land use within each square: LU1-old-growth forest (100\%); LU2-managed forest (100\%); LU3 - forest-dominated ( $>50 \%)$ mosaic; LU4-mixed-use mosaic $(50 \%$ forest, 50\% open, agricultural habitats); LU5-grasslanddominated $(>50 \%)$ and LU6-arable-dominated $(>50 \%)$. Replication of LU types was limited by logistical and financial constraints associated with the wider pan-European research project (EU Framework 5 "BioAssess" project) in which this study was embedded. Within each LU we sampled on a systematic grid of 16 sampling points, with each sampling point at least $200 \mathrm{~m}$ from neighbouring points and the edge of the $1 \mathrm{~km}$ square. This gave a distribution of points within the realised habitat proportions of each LU (Table 1; note: LU4 has 15 sampling points because of a restriction on accessing arable fields in LU4, hence sampling point $n=95$ in subsequent analyses). LU1 and LU2 were dominated by Pinus sylvestris forest (small patches of Pinus contorta and Picea sitchensis occurred in LU2); LU3 supported extensive areas of Pinus sylvestris forest but also supported patches of Larix decidua, deciduous woodland (Quercus robur, Betula pendula, Sorbus aucuparia) and permanent pasture; LU4 was a mixture of coniferous plantation (Pinus sylvestris, L. decidua, Picea abies, P. sitchensis), deciduous woodland (Acer pseudoplatanus, B. pendula, S. aucuparia), improved pasture and arable (barley) cropping; LU5 and LU6 were dominated by rotational agriculture (pasture, silage, arable) with only minor forest elements and isolated trees. Interviews with landowners revealed no major historical changes between forest and agriculture cover with the predominant land use in each LU being unchanged for greater than 50 years. Only minor management changes have occurred over the last 20-50 years: LU1: deer numbers reduced 1996-2002; LU2: constant forest cover for $>50$ years, but with plantation forestry established in 1960; LU3: plantation forestry in six sampling points established in 1960 (previously natural forest and moorland); LU4: L. decidua cover maintained during selective felling of Pinus sylvestris in two mixed forest sampling points in 1990; LU5: Pinus sitchensis plantation on one sampling point since 1983; LU5 and 6: general agricultural intensification over preceding 30 years with increased barley cropping and improved grass varieties/ mixtures. Given the lack of land use change from forest to agriculture in the studied landscapes-and accepting the normal practice of 2-3 year rotations between improved grassland and barley crops in the agricultural areas of LU4, 5 and 6-we assume that patterns in soil diversity could be safely attributed to the current land-use-driven patterns in habitat heterogeneity. For a map and additional details of the study sites see Vanbergen et al. (2005), Eggleton et al. (2005), respectively.

\section{Soil fauna}

Soil fauna were sampled in two years (Collembola: September 2001, April-May 2002; Lumbricidae: May 2001 and 2002) timed to coincide with maximum species diversity (Deharveng 1996). At each sampling point in both years Collembola were sampled with a soil core $(5 \mathrm{~cm}$ diameter $\times 5 \mathrm{~cm}$ depth) giving a total of 190 samples; the soil cores were transferred to the laboratory and Collembola extracted over 14 days using Tullgren funnels (Hopkin 2000). The specimens were individually slide-mounted and identified to species at the Centre for Ecology and Hydrology using standard keys (Fjellberg 1998; Hopkin 2000). Lumbricid worms were sampled at each sampling point (total $=190$ samples over 2 years) with a steel frame quadrat $(25 \mathrm{~cm} \times 25 \mathrm{~cm} \times 15 \mathrm{~cm}$ deep $)$ forced into the ground; the litter and soil monolith was excavated and hand-sorted on trays for lumbricids. When soil had been excavated down to the base of the quadrat $(15 \mathrm{~cm}$ depth) 1.51 of a $0.02 \%$ formalin solution was applied to the exposed soil surface and worms emerging over a 10-min period were collected. Lumbricid worms were identified to species at the Natural History Museum, London, UK (Sims and Gerard 1999).

Landscape- and local-scale habitat elements

The landscape-scale habitat composition and structure of the LUs was assessed using remotely sensed land-cover data. Two satellite images of the study area were used, a Landsat 7 ETM+ multispectral image and an IRS-1C 


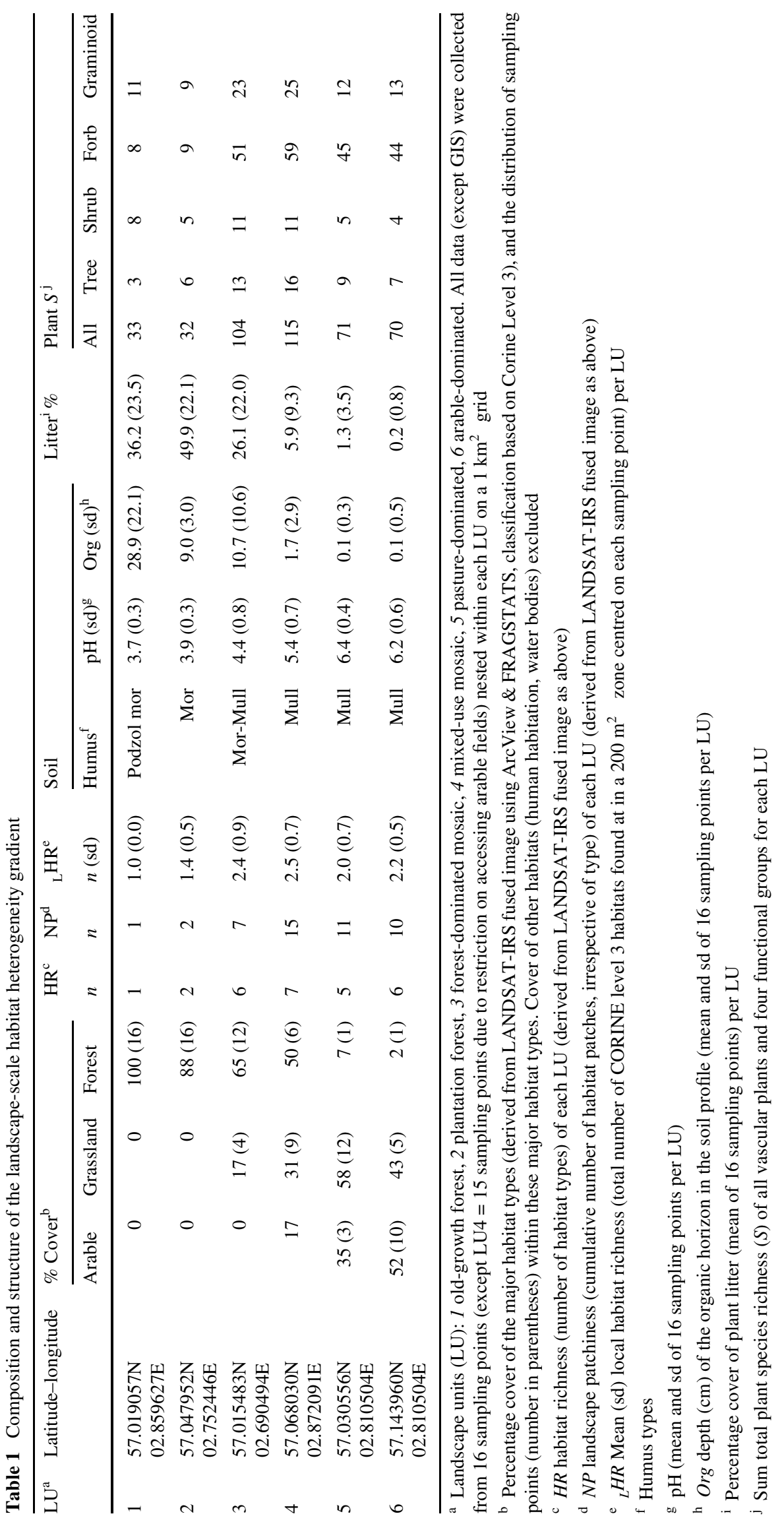


panchromatic image, to create a single fused image with a $5 \mathrm{~m}$ spatial resolution for each LU. A hierarchic classification system based on the CORINE (Level 3 nomenclature) biotopes database (European Environment Agency) was defined and used to interpret visually the satellite images using GIS (Arcview 3.1). The reliability of this land-cover classification was checked against personal knowledge of the study area and, where required, ground visits. This CORINE classification was used to quantify, using FRAGSTATS software, patterns in land cover enabling three indices of landscape-scale $\left(1 \mathrm{~km}^{2}\right)$ habitat heterogeneity to be derived for each LU: percentage cover of forest, habitat richness (number of habitats) and landscape patchiness (cumulative number of habitat patches irrespective of type and size). Local-scale habitat richness was estimated by taking the number of distinct habitats (using the same CORINE Level 3 classification as for the landscape-scale) observed (using GIS maps and ground-knowledge) to be present in a $200 \mathrm{~m}^{2}$ zone including each sampling point plus four points on the grid $200 \mathrm{~m}$ north, south, east and west of each sampling point.

Habitat quality: plant assemblages

Information on the composition and structure of the plant assemblage was collected at each of the 16 sampling points within each LU from 14 May to 12 July 2001. Plant sampling coincided with the point in the growing season of maximum plant species density. A plot $100 \mathrm{~m}^{2}$ $(20 \mathrm{~m} \times 5 \mathrm{~m})$ in area was laid down around the centre of the sampling point. This rectangular plot was composed of two sets of nested subplots of 1, 5, 12.5, 25 and $50 \mathrm{~m}^{2}$ within which the identity and number of plant species were measured. The cumulative total number of vascular plant species sampled within the $100 \mathrm{~m}^{2}$ plot and the species richness of plant functional groups (trees, shrubs, forbs, graminoids) was derived from this dataset following standard nomenclature (Stace 1997). The percentage cover of litter was visually estimated and agreed by two observers to a $5 \%$ interval in a $0.2-\mathrm{m}^{2}$ plot nested within the $100-\mathrm{m}^{2}$ plot at each sampling point. Tree canopy percentage cover above each sampling point was measured with a spherical densiometer (Forestry Suppliers Inc., Jackson, MS, USA).

Habitat quality: soils

Soil $\mathrm{pH}$ and the depth of the organic (O) horizon (in $\mathrm{mm}$ ) were determined at each sampling point using a portable pH probe (Hanna HI 9024 microcomputer, Hanna Instruments Ltd., Leighton Buzzard, UK) and by excavating a pit to reveal the soil profile, respectively. Three measures of each parameter were taken at each sampling point and averaged to give the mean $\mathrm{pH}$ and depth of the organic horizon at the sampling point.

Data analysis

Collembola and lumbricid juveniles were excluded from all analyses except the analyses of total Collembola and lumbricid abundance (see below). Principal components analysis (PCA) was used to assess whether samples $(n=95)$ from different LUs along the gradient of habitat heterogeneity supported distinct soil fauna assemblages (ter Braak and Smilauer 1998); correlation between the first and second principal components and measured environmental variables was assessed using Spearman's correlation coefficient. Compositional similarity among soil fauna samples from within each LU $(n=16$, except LU4 =15) was assessed using Jaccard's similarity index $\left(C_{\mathrm{J}}=j /\right.$ $(a+b-j)$, where $j$ is the number of species common to two samples, and $a$ and $b$ are the total number of species in each sample; $C_{\mathrm{J}}=1.0$ indicates a perfectly homogeneous species assemblage (Colwell 2005).

Generalised linear models (GLMs) using a Poisson error distribution and a log link function were used to correlate, at both local (95 sampling points) and landscape (six LUs) spatial scales, soil fauna diversity (counts of species and individuals) with different elements and qualities of the habitat heterogeneity gradient. For the local-scale analysis, the counts of species and individuals were correlated with the main effects: landscape unit (LU), local habitat richness (in a $200 \mathrm{~m}^{2}$ area centred on each sampling point), the plant species richness, tree canopy $(\%)$ and plant litter $(\%)$ cover, soil $\mathrm{pH}$ and depth of O-horizon $(\mathrm{cm})$ recorded at each sampling point. Landscape unit was always fitted prior to the remaining main effects to account for landscape-scale variance in soil fauna diversity, and control for the lack of independence of sampling points within a landscape unit, when testing for variance due to local-scale factors. Local-scale explanatory terms were thereafter fitted by forward selection. The relative influence of colinear explanatory variables on soil fauna diversity was addressed by varying the order in which dependent variables were fitted and comparing sequential (Type 1) and adjusted (Type 3 ) $\chi^{2}$ tests (SAS 9.1, SAS Institute, Cary, NC, USA). Model simplification was achieved through deletion of the least significant term, and results of Type 1 tests are reported.

For the landscape-scale analysis soil fauna data from sampling points were pooled to provide sum counts of Collembola and lumbricid species and individuals for each LU. Plant species richness data were also summed for each LU and, together with landscape metrics (forest \% cover, habitat richness, landscape patchiness) per LU, the average cover of plant litter, the soil $\mathrm{pH}$ and the depth of the O-horizon (Table 1) were used as explanatory terms in the 
landscape-scale statistical analysis. Owing to the intercorrelation between the various explanatory terms and the limited degrees of freedom at this spatial scale $(n=6)$, which confounded multivariate regression, only the univariate effect of each covariate on Collembola and lumbricid species richness and abundance are reported. An exact test (720 permutations) was used to determine the significance of the observed GLM deviance for each explanatory term (SAS 9.1). This test gives the exact probability that a deviance as small as that obtained by the fitted GLM-using the correct matching of the six explanatory variable values to the six response variable values-could have occurred by chance under the null hypothesis that the data values were allocated to LU squares at random. This test is less powerful than a parametric test for significance of univariate relationships, but it has the advantage of being robust against departures from the model assumed by the fitted GLM.

\section{Results}

Temporal changes in soil fauna diversity

Sampling year did not significantly influence the diversity or abundance of either Collembola or lumbricids (species richness: Collembola $-\chi_{(1,188)}^{2}=0.30, P=0.59$, lumbricids $\chi_{(1,188)}^{2}=3.69, P=0.06$; abundance: Collembola $-\chi^{2}$ ${ }_{(1,188)}=0.77 P=0.38$, lumbricids $\left.\chi_{(1,188)}^{2}=0.74, P=0.39\right)$. This made it unnecessary to include sampling year as a covariate, and for all subsequent analyses data from both years was pooled to give a single count of species and individuals at each sampling point or LU.

Compositional turnover along the habitat heterogeneity gradient

Both Collembola and lumbricid assemblages showed considerable turnover in species composition along the habitat heterogeneity gradient (see Fig. 1 and the "Electronic supplementary material"). Collembola assemblages were clearly separated along the first PCA axis according to whether they were sampled from the forest-dominated (LU1 and 2) or agriculture-dominated (LU5 and 6) landscapes, with the assemblages from the habitat mosaics (LU3 and 4) situated at the intermediate point of this gradient in species composition (Fig. 1a). This Collembola assemblage turnover (PCA axes 1) was positively correlated with the presence of forest cover and associated soils (Spearman's correlation coefficient: tree canopy density 0.49 , plant litter cover 0.63 , depth of O-horizon $0.65, P<0.001$ ) and negatively correlated with increasing soil $\mathrm{pH}$ (soil $\mathrm{pH}-0.62$, $P<0.001)$. Lumbricid assemblages were principally separated along the first PCA axis (plant species richness 0.44,
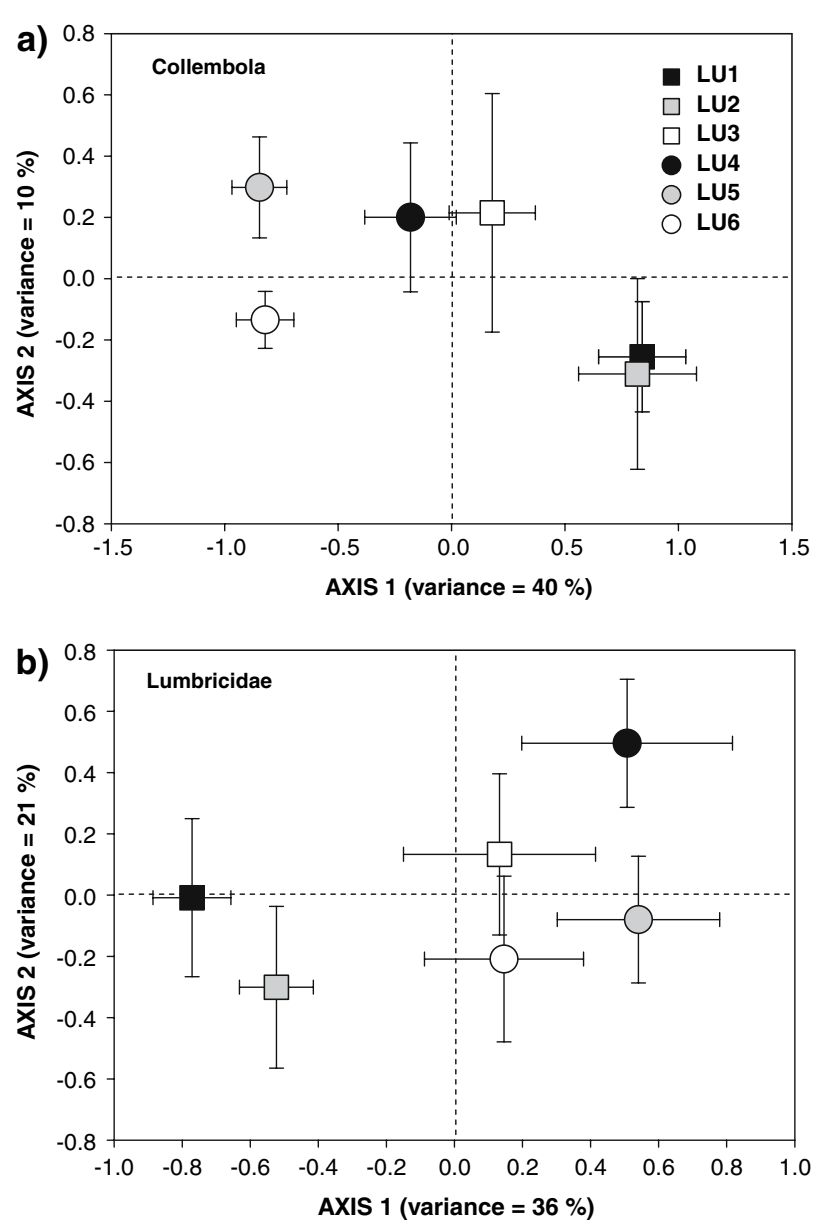

Fig. 1a-b Principal components analysis of a Collembola and b lumbricid worm assemblages along a landscape-scale gradient of habitat heterogeneity. Landscape units (LU) consist of: (LU1) old-growth forest, (LU2) plantation forest, (LU3) forest-dominated mosaic, (LU4) mixed-use mosaic, (LU5) pasture- and (LU6) arable-dominated sites. Symbols are mean (15-16 sampling points per LU) sample scores \pm SE; circles and squares denote LUs with $\leq 50$ and $\geq 65 \%$ forest cover, respectively. Variance (\%) in the species data contained in each principal component axis is shown in parentheses

soil pH 0.52, plant litter cover -0.53 , depth of Ohorizon $-0.58, P<0.001)$, with acidic, plant-species-poor forest sites (LU1 and 2) separated from the less acidic and plant-species-rich habitat mosaics (LU3 and 4) and the high $\mathrm{pH}$ agricultural landscapes (LU5 and 6) (Fig. 1b). The mosaic (LU3 and 4) landscapes were further separated from the other sites along the second PCA axis (Fig. 1b), correlated with plant species $(0.38, P<0.001)$ and local habitat $(0.33, P<0.001)$ richness.

Correlates of soil fauna diversity: habitat elements

Our first hypothesis- that the landscapes with the greatest habitat richness would support the greatest diversity of soil 
fauna-was upheld at the landscape (Fig. 2) but not the local spatial scale (Table 2). Local-scale habitat richness-number of habitats (CORINE level 3 classification) present in a $200 \mathrm{~m}^{2}$ zone centred on each sampling point — did not significantly influence the soil fauna species richness or abundance observed at each sampling point (Table 2), hence there is no evidence that the available data supports the hypothesis that local-scale habitat richness was structuring soil fauna diversity in these sites. At the landscape scale, however, soil fauna species richness peaked where a mixture of forest and open habitats occurred (LU4) ("Electronic supplementary material", Table 1, Fig. 2a,c). Collembola and lumbricid species richness and lumbricid abundance showed a significant, humpshaped relationship with forest percentage cover in the surveyed landscapes (Fig. 2a,b, Table 3). Collembola species richness reached a maximum where forest and woodland was reduced to $50-65 \%$ of the $1 \mathrm{~km}^{2}$; lumbricid species richness and abundance peaked where grassland occupied 17$58 \%$ and $31-58 \%$ of the $1 \mathrm{~km}^{2}$, respectively (Table 1 , Fig. 2a,b). Collembola abundance declined monotonically with the decrease in forest percentage cover per LU along the habitat heterogeneity gradient (Fig. 2b, Table 3). Landscapescale habitat richness was positively related to lumbricid richness and abundance (Fig. 2c, Table 3), and also to Collembola species richness-although marginally nonsignificant (Table 3). Collembola abundance was negatively and lumbricid abundance positively correlated with landscape patchiness - the number of distinct habitat patches irrespective of type and size (Fig. 2d, Table 3). This latter result is perhaps a reflection of the habitat preferences of the two taxa: Collembola numerically dominating samples from the single habitat forest landscapes and lumbricids dominating the spatially patchy mosaic (forest and grassland) and agricultural (grassland and arable) soils, where much of the landscape was under grassland management.

The observed peak in soil fauna species richness in the landscape-scale habitat mosaics was accompanied by a greater turnover in species composition among sampling points within those same landscapes. For both Collembola and lumbricids, the Jaccard similarity index $\left(C_{\mathrm{J}}=1.0\right.$ indicates a perfectly homogeneous species assemblage) revealed that the degree of compositional similarity between samples was much lower within the landscapes with greater habitat richness and patchiness (LU3: Collembola 0.14 , lumbricids 0.48 ; LU4: Collembola 0.46, lumbricids 0.41; LU5: Collembola 0.55, lumbricids 0.49) compared to the compositional similarity among samples from the forest-dominated (LU1: Collembola 0.84, lumbricids 1.0; LU2: Collembola 0.76, lumbricids 0.92) and arable-dominated (LU6: Collembola 0.77, lumbricids 0.94) landscapes. As the landscapes became less dominated by a single habitat (old-growth or plantation forest, or arable) and habitat heterogeneity (richness and patchiness) increased (Table 1), the turnover in species composition increased accordingly. There was, therefore, strong evidence that the diversity of both soil taxa in these studied landscapes was governed by habitat heterogeneity at landscape but not local spatial scales.
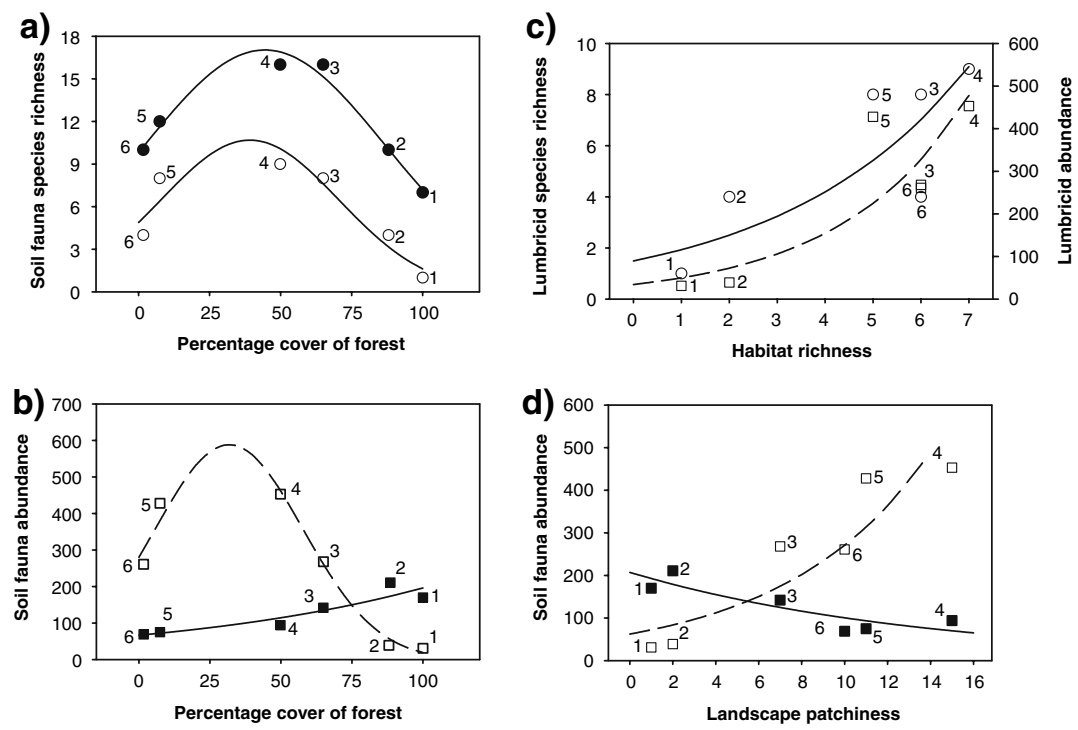

Fig. 2a-d The observed and fitted landscape-scale (LU) relationships of a soil fauna species richness with the percentage cover of forest; $\mathbf{b}$ soil fauna abundance with the percentage cover of forest; $\mathbf{c}$ lumbricid species richness and abundance with habitat richness; d soil fauna abundance with landscape patchiness. Species richness: Collembola-

closed circles, solid line; Lumbricidae-open circles, solid line. Abundance: Collembola-closed squares, solid line; Lumbricidae-open squares, dashed line. Symbol labels indicate LU number and land use: 1 , old-growth forest; 2 , plantation forest; 3 , forest-dominated mosaic; 4 , mixed-use mosaic; 5 , pasture- and 6 , arable-dominated 
Table 2 Local-scale $(n=95)$ correlates of soil fauna diversity: results from generalised linear models using a Poisson error distribution and a log link function

\begin{tabular}{|c|c|c|c|c|c|c|c|c|}
\hline \multirow[t]{3}{*}{ Independent variable } & \multicolumn{4}{|l|}{ Collembola } & \multicolumn{4}{|l|}{ Lumbricids } \\
\hline & \multicolumn{2}{|c|}{ Species richness } & \multicolumn{2}{|l|}{ Abundance } & \multicolumn{2}{|c|}{ Species richness } & \multicolumn{2}{|l|}{ Abundance } \\
\hline & $\chi_{(\text {ndf, ddf) }}^{2}$ & $P$ & $\chi_{(\mathrm{ndf}, \mathrm{ddf})}^{2}$ & $P$ & $\chi_{(\mathrm{ndf}, \mathrm{ddf})}^{2}$ & $P$ & $\chi_{(\text {ndf, ddf) }}^{2}$ & $P$ \\
\hline Landscape unit (LU) & $10.94_{(5,89)}$ & 0.05 & $32.95(5,88)$ & $<0.001$ & $39.75_{(5,88)}$ & $<0.001$ & $116.79(5,87)$ & $<0.001$ \\
\hline Habitat diversity (local) & $1.17_{(1,88)}$ & 0.28 & $1.35_{(1,88)}$ & 0.25 & $1.02_{(1,87)}$ & 0.31 & $0.98_{(1,88)}$ & 0.32 \\
\hline Plant species richness & $0.87_{(1,88)}$ & 0.35 & $0.53_{(1,87)}$ & 0.47 & $12.10_{(1,88)}$ & 0.005 & $9.60_{(1,87)}$ & 0.002 \\
\hline Plant litter cover $(\%)$ & $1.36_{(1,88)}$ & 0.24 & $0.80_{(1,87)}$ & 0.37 & $0.17_{(1,87)}$ & 0.68 & $2.85_{(1,87)}$ & 0.09 \\
\hline Tree canopy density (\%) & $0.03_{(1,88)}$ & 0.85 & $0.01_{(1,87)}$ & 0.93 & $3.41_{(1,87)}$ & 0.07 & $18.56_{(1,87)}$ & $<0.001$ \\
\hline Soil pH & $0.67_{(1,88)}$ & 0.41 & $2.66_{(1,87)}$ & 0.10 & $0.09_{(1,86)}$ & 0.76 & $0.06_{(1,86)}$ & 0.81 \\
\hline Soil O-horizon $(\mathrm{cm})$ & $0.49_{(1,88)}$ & 0.48 & $0.04_{(1,87)}$ & 0.85 & $3.38_{(1,87)}$ & 0.07 & $2.44_{(1,86)}$ & 0.12 \\
\hline
\end{tabular}

Table 3 Landscape-scale $(n=6)$ correlates of soil fauna diversity: results of exact tests (720 permutations) of the deviance $(D)$ in soil fauna species richness and abundance explained by each univariate generalised linear model (GLM) using a Poisson error distribution and a log link function

\begin{tabular}{|c|c|c|c|c|c|c|c|c|c|c|c|c|}
\hline \multirow[t]{3}{*}{ Independent variable } & \multicolumn{6}{|c|}{ Collembola } & \multicolumn{6}{|c|}{ Lumbricids } \\
\hline & \multicolumn{3}{|c|}{ Species richness } & \multicolumn{3}{|c|}{ Abundance } & \multicolumn{3}{|c|}{ Species richness } & \multicolumn{3}{|c|}{ Abundance } \\
\hline & $\bar{D}$ & $D^{2}$ & $P$ & $\bar{D}$ & $D^{2}$ & $P$ & $\bar{D}$ & $D^{2}$ & $P$ & $\bar{D}$ & $D^{2}$ & $P$ \\
\hline \multicolumn{13}{|l|}{ Lumbricids } \\
\hline Species richness & 0.73 & 0.87 & 0.006 & 111.64 & 0.12 & 0.38 & - & & - & - & & - \\
\hline Abundance & 2.82 & 0.49 & 0.12 & 86.70 & 0.32 & 0.20 & - & & - & - & & - \\
\hline \multicolumn{13}{|l|}{ Collembola } \\
\hline Species richness & - & & - & - & & - & 2.81 & 0.73 & 0.02 & 256.42 & 0.69 & 0.12 \\
\hline Abundance & - & & - & - & & - & 9.04 & 0.12 & 0.33 & 289.84 & 0.65 & 0.15 \\
\hline \multicolumn{13}{|l|}{ Landscape elements ${ }^{\mathrm{a}}$} \\
\hline Forest (\%) & 0.12 & 0.98 & 0.006 & 15.61 & 0.88 & 0.01 & 1.34 & 0.87 & 0.005 & 23.15 & 0.97 & 0.01 \\
\hline Habitat richness $(n)$ & 1.76 & 0.68 & 0.06 & 54.42 & 0.57 & 0.12 & 3.89 & 0.62 & 0.03 & 199.20 & 0.76 & 0.02 \\
\hline Landscape patchiness $(n)$ & 2.99 & 0.46 & 1.44 & 32.81 & 0.74 & 0.04 & 4.75 & 0.54 & 0.07 & 164.28 & 0.80 & 0.004 \\
\hline \multicolumn{13}{|l|}{ Plant variables ${ }^{\mathrm{b}}$} \\
\hline Vascular S & 0.83 & 0.85 & 0.03 & 82.40 & 0.35 & 0.23 & 3.78 & 0.63 & 0.03 & 350.61 & 0.57 & 0.02 \\
\hline Tree $S$ & 0.43 & 0.92 & 0.006 & 104.77 & 0.18 & 0.40 & 3.13 & 0.70 & 0.02 & 418.77 & 0.49 & 0.07 \\
\hline Shrub S & 3.20 & 0.42 & 0.19 & 126.27 & 0.01 & 0.85 & 8.66 & 0.16 & 0.35 & 783.53 & 0.05 & 0.58 \\
\hline Forb S & 1.55 & 0.72 & 0.03 & 50.66 & 0.60 & 0.09 & 3.17 & 0.69 & 0.005 & 120.40 & 0.85 & 0.01 \\
\hline Graminoid S & 1.36 & 0.76 & 0.03 & 112.9 & 0.11 & 0.39 & 5.99 & 0.42 & 0.14 & 584.41 & 0.29 & 0.15 \\
\hline Plant litter (\%) & 4.84 & 0.13 & 0.48 & 2.77 & 0.98 & 0.001 & 7.85 & 0.24 & 0.28 & 256.13 & 0.69 & 0.03 \\
\hline \multicolumn{13}{|l|}{ Soil variables ${ }^{\mathrm{c}}$} \\
\hline $\mathrm{pH}$ & 5.24 & 0.06 & 0.60 & 6.64 & 0.95 & 0.008 & 8.39 & 0.19 & 0.32 & 377.60 & 0.54 & 0.08 \\
\hline O-horizon $(\mathrm{cm})$ & 4.01 & 0.28 & 0.31 & 75.21 & 0.41 & 0.17 & 5.54 & 0.46 & 0.11 & 327.25 & 0.60 & 0.05 \\
\hline
\end{tabular}

The exact test gives the exact probability that the deviance as small as that obtained by the fitted GLM could have occurred through chance differences between LU squares other than the tested parameter. Deviance squared ( $D^{2}=1-$ residual deviance/null deviance) gives the proportion of deviance explained by each univariate model

${ }^{a}$ Derived for each LU from LANDSAT-IRS fused image using ArcView \& FRAGSTATS

${ }^{\mathrm{b}}$ Sum total species richness $(S)$ of vascular plants and functional groups and mean percentage cover of litter. Data collected from 16 sampling points nested within each LU on a $1 \mathrm{~km}^{2}$ grid

${ }^{\mathrm{c}}$ Soil $\mathrm{pH}$ and the depth of the organic horizon in the soil profile. Data analysed are mean values of 16 sampling points nested within each LU on a $1 \mathrm{~km}^{2}$ grid 


\section{Correlates of soil fauna diversity: habitat qualities}

Only partial evidence was found for our second hypothesis, that soil taxon identity would determine which qualities of the habitat heterogeneity gradient affected diversity. There was strong evidence that the LU from which a sample originated was always a significant influence on the local-scale soil fauna species richness and abundance (Table 2). After accounting for this landscape-scale variance no evidence of local-scale factors affecting local Collembola diversity was found (Table 2). In contrast, local-scale lumbricid species richness and abundance was positively correlated with vascular plant species richness, and lumbricid abundance was negatively correlated with increasing tree canopy density (Fig. 3, Table 2). At the landscape-scale, however, plant species richness was a significant predictor of both Collembola and lumbricid species richness. Contrary to the prediction that soil taxon identity would govern which plant functional group (trees or forbs) correlated with soil taxon diversity, the species richness of both soil taxa was positively correlated with both tree and forb species richness (Fig. 4a,b). It appeared, however, that Collembola species richness was more strongly related to tree rather than forb species richness, while lumbricid species richness showed the opposite, albeit less pronounced, trend (Table 3). Moreover, while lumbricid abundance was positively related to forb species richness, Collembola abundance was independent of species richness in all plant functional groups (Table 3). While soil fauna richness and abundance was independent of soil variables at local scales (Table 2), Collembola abundance was positively and negatively correlated with plant litter cover and soil $\mathrm{pH}$, respectively, at landscape scales (Fig. 4c,d, Table 3), and lumbricid abundance was negatively, but more weakly, correlated with plant litter cover (Fig. 4c, Table 3).

\section{Discussion}

In accord with our first hypothesis, evidence was found at the landscape-scale that soil fauna species richness and turnover peaked where a decrease in the percentage cover of coniferous forest and a concomitant increase in broadleaf, grassland and arable habitat cover resulted in a habitat mosaic. The likely explanation for this hump-shaped diversity relationship is the presence of more ecological niches in habitat mosaics, allowing both species colonisation and population persistence in the landscape (MacArthur and Wilson 1967; Hanski 1999; Benton et al. 2003; Bardgett et al. 2005); an interpretation supported by the positive relationship found between lumbricid diversity and habitat richness per landscape. Lumbricid abundance was also positively related to landscape patchiness-number of habitat
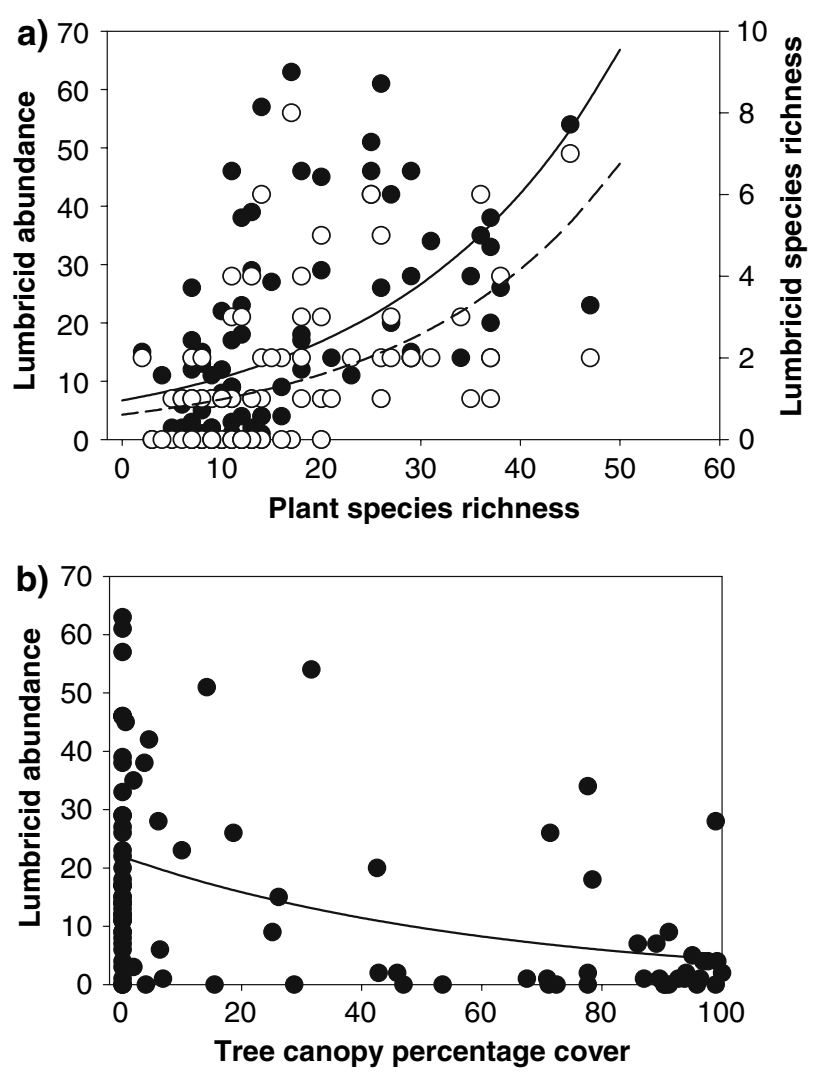

Fig. 3a-b The local-scale (95 sampling points) relationships of a lumbricid species richness (open symbols, dashed line) and abundance (closed symbols, solid line) with plant species richness; and b lumbricid abundance with tree canopy percentage cover

patches irrespective of type and size-which may indicate the role of spatial landscape patchiness in providing refuges for lumbricid worm populations from anthropogenic disturbance (e.g. tillage, Bardgett et al. 2005). In contrast, Collembola abundance was negatively related to the decline in forest cover and concomitant increase in landscape patchiness along the habitat heterogeneity gradient. Differences in which landscape elements influence diversity are often taxon- or functional-group-specific (Steffan-Dewenter et al. 2002; Chust et al. 2004; Dauber et al. 2005; Purtauf et al. 2005); and here perhaps reflect the distinct ecological requirements of each taxon. The predominantly fungivorous Collembola depend on the presence of a relatively undisturbed plant detritus food web (Ponge et al. 1993; Bardgett and Cook 1998; Hedlund and Ohrn 2000; Hopkin 2000) (but see Salamon et al. 2006) of forest and no-tillage, low-intensity pasture ecosystems. Conversely, lumbricid worms are nearly absent from acidic forest soils, and have a reduced dependence on soil microbial communities as primary decomposers (Bardgett and Cook 1998; Maraun et al. 2003; Bardgett et al. 2005).

The hypothesis that soil taxon identity would determine which qualities of the habitat gradient influence soil diversity 
Fig. 4a-d The observed and fitted landscape-scale (LU) relationships of soil fauna species richness with a tree species richness and $\mathbf{b}$ forb species richness; and those of soil fauna abundance with $\mathbf{c}$ plant litter percentage cover and $\mathbf{d}$ soil $\mathrm{pH}$. Collembola: closed circles, solid line; lumbricids: open circles, dashed line. Symbol labels indicate LU number and land use: 1 , old-growth forest, 2, plantation forest, 3 , forest dominated mosaic, 4 , mixed-use mosaic, 5 , pasture and 6 , arable-dominated
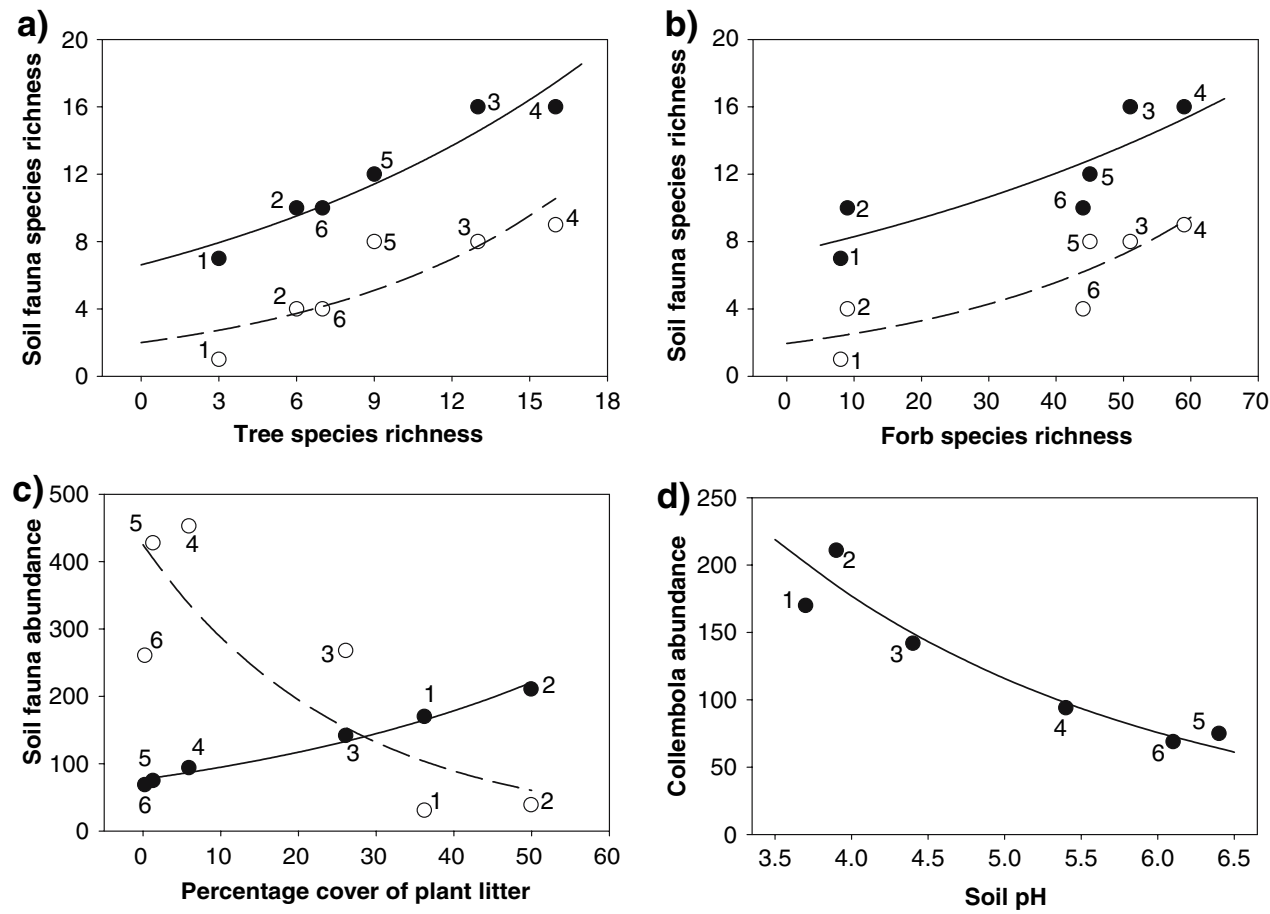

was partly upheld. Despite correlations between above- and belowground diversity being generally uncommon (Hooper et al. 2000; Wardle et al. 2003; St John et al. 2006), plant diversity was positively correlated with the species richness of both Collembola and lumbricids and with lumbricid abundance in this study. There was some support for the prediction that the different soil taxa would respond to diversity within different plant functional groups: at the landscape scale, tree species richness explained more of the deviance in Collembola species richness than other plant functional groups, while forb species richness had the greater influence on lumbricid richness and abundance compared with other plant functional groups. It is possible that these positive relationships between above- and belowground diversity arose from a direct relationship between plant and soil diversity, mediated by increasing diversity of the litter resource underpinning the soil assemblage (Ponge et al. 1993; Hansen and Coleman 1998; De Deyn et al. 2004). Because, however, we did not evaluate litter diversity, we have no evidence to substantiate this interpretation. More likely, in this case (as elsewhere; see Gillison et al. 2003), these correlations have arisen as a consequence of land-use-driven habitat heterogeneity affecting plant and soil diversity similarly-both soil and plant diversity show identical hump-shaped relationships with the habitat heterogeneity gradient (Table 1). These differences, together with changes in plant litter cover and soil $\mathrm{pH}$, again reflect the changes in forest cover along the habitat gradient and also the relative habitat preferences of each soil taxa mentioned above.
Our hypotheses and predictions were only partially supported because these correlations between soil fauna diversity and both elements and qualities of habitat heterogeneity were not consistent between the landscape and local spatial scales. Despite the shape of the gradient in mean local habitat richness per LU (Table 1) matching that of the landscape-scale habitat richness, there was no effect of this parameter on the diversity of either taxon. This may be because the range of observed (from GIS maps and ground knowledge) habitats was lower at local (range 1-4 habitats) than at landscape (range 1-7 habitats) scales, which might have meant that the local-scale habitat richness gradient was insufficient to produce detectable variation in species diversity.

Soil taxon identity determined not only which elements and qualities of the habitat gradient influenced diversity, but also the sensitivity of each individual taxon to habitat heterogeneity at different spatial scales. Forest percentage cover was a good landscape-scale predictor of the diversity of both Collembola and lumbricid diversity; however, at local scales only lumbricid abundance was negatively related to tree canopy cover. Soil taxon identity also influenced the scale-dependent response to plant diversity: strong positive relationships between both taxa and plant diversity at landscape-scales did not persist at the local scale, where only lumbricid diversity remained positively correlated with plant species richness. These differences in the response of a single taxon to the various facets of habitat heterogeneity at different spatial scales have been observed in other systems (Brose 2003; Tews et al. 2004; 
Bardgett et al. 2005). The positive and negative relationships between lumbricid diversity and plant diversity and tree canopy cover, respectively, indicate the known habitat preferences of this taxon for grassland mull soils (Bardgett et al. 2005; Eggleton et al. 2005). Given the strong correlation between diversity and both habitat elements and qualities at the landscape scale, it is initially surprising to find no evidence of a Collembola diversity relationship with local-scale gradients in habitat heterogeneity, especially when we consider the evidence published elsewhere (Hopkin 1997; Ims et al. 2004; Cole et al. 2005; Hoyle and Harborne 2005). The reason for the scale-specific correlations between Collembola diversity and habitat heterogeneity is not apparent from these data. It might be, however, that while large-scale patterns in land use generate habitat structure that may, over time, affect Collembola diversity by influencing passive population dispersal and differential persistence among patches of varying quality (Dunger et al. 2002; Ettema and Wardle 2002; Ponge et al. 2003, 2006; Ims et al. 2004), the local-scale employed here did not capture either those coarse-scale ecological processes (dispersal, patch dynamics) or the processes (competition, predation, facilitation) that occur on the microscale (i.e. centimetres) at which these small-bodied soil mesofauna operate (Ettema and Wardle 2002; Bardgett et al. 2005). By this reasoning, it is perhaps less surprising that the diversity of lumbricid worms-larger-bodied, mobile soil macrofauna-is influenced by heterogeneity in tree cover and plant diversity at the local-scale (i.e. metres).

Two caveats should be noted when considering our findings. First, sample size was limited at the landscape scale due to logistical and financial constraints associated with the wider research framework (EU Framework 5 BioAssess project) in which this study was embeddedhence the data basis at this scale is comparatively poor and landscape-scale results should be treated with appropriate caution. This low sample size at the landscape scale also presents analytical problems: because of insufficient degrees of freedom we are not able to assess with multivariate regression the relative contribution to diversity of the different elements and the qualities of habitat heterogeneity. The robustness of each univariate relationship, however, was tested by exact tests on the deviance explained by each fitted covariate; this demonstrated the probability that a deviance as small as that obtained could have occurred through chance differences between LU squares other than the fitted covariate. Therefore, despite low sample size, we are confident in the robustness of the observed and modelled patterns in diversity. Second, while all sampling by definition represents a snapshot, the restriction of this study to a single sampling occasion within each year may introduce a potential bias into the data due to the acknowledged high levels of spatiotemporal heterogeneity in soils (Bardgett et al. 2005). However, timing the sampling to coincide with maximum seasonal diversity together with the lack of between-year-and therefore for Collembola betweenseason-differences in soil taxon diversity gives us some confidence that our samples are representative of the species assemblage.

The observed patterns in soil faunal diversity were more strongly correlated with elements and qualities of habitat heterogeneity at landscape rather than local scales. This concurs with other recent studies (Chust et al. 2004; Dauber et al. 2005; Eggleton et al. 2005; Joschko et al. 2006; Sousa et al. 2006) that show that coarsescale environmental heterogeneity arising from land use can influence the diversity and abundance of soil faunaspecies that operate at fine spatial scales. The greatest species turnover and hence species richness of both soil taxa (and plants) occurred where an approximately even mixture of forest and grassland habitats was present. This study and others (Eggleton et al. 2005; Sousa et al. 2006) indicates how comparatively small patches of broadleaf woodland (LU3 and 4: 7-15\% per $1 \mathrm{~km}^{2}$ ) in landscapes dominated by agricultural and forestry monoculture contribute disproportionately to an area's soil fauna diversity. Forest plantation and arable landscapes supported a relatively species-poor fauna, as did Caledonian pinewood (LU1), although from a conservation perspective the latter habitat is known to be dominated by soil macrofauna (e.g. millipedes) of restricted geographical range (Eggleton et al. 2005). This study adds to the evidence that landscape-scale habitat heterogeneity does drive soil fauna species diversity (Ettema and Wardle 2002; Eggleton et al. 2005; Sousa et al. 2006). The mechanism is likely to be the provision of additional niche space, refuges from disturbance and passive dispersal of soil fauna in a metapopulation structure (Hanski 1999; Ettema and Wardle 2002). The maintenance and creation of landscape-scale habitat mosaics may be desirable management prescriptions as part of a strategy for the conservation of soil biodiversity. Furthermore, while landscape-scale heterogeneity structures soil fauna diversity regardless of functional or taxonomic identity, the influence of habitat heterogeneity at smaller scales is dependent on identity, and therefore on ecological traits such as body size and mobility (Ettema and Wardle 2002). Therefore, it is possible that landscape patterns in land use-together with microhabitat heterogeneity not measured here-will drive variation in soil species diversity, which will feedback to plant productivity via altered nutrient recycling, and ultimately may influence ecosystem function (Ettema and Wardle 2002; Bardgett et al. 2005). 
Acknowledgements Thanks to C. Beaudoin, C. Dawson and B. Woodcock for assistance in the laboratory and field, D. Elston (Biomathematics and Statistics Scotland) for statistical advice, and L. Cole for valued comments. Thanks also to landowners for permission to work on their land, and to the late S. Hopkin for confirming Collembola species identification, as well as to the anonymous referees whose suggestions greatly improved this paper. The EU Framework Programme 5 funded this work (BioAssess research project EVK4-199900280).

\section{References}

Andresen E (2003) Effect of forest fragmentation on dung beetle communities and functional consequences for plant regeneration. Ecography 26:87-97

Bardgett RD, Cook R (1998) Functional aspects of soil animal diversity in agricultural grasslands. Appl Soil Ecol 10:263-276

Bardgett RD, Yeates GW, Anderson JM (2005) Patterns and determinants of soil biological diversity. In: Bardgett RD, Usher MB, Hopkins DW (eds) Biological diversity and function in soils. Cambridge University Press, Cambridge, UK

Benton TG, Vickery JA, Wilson JD (2003) Farmland biodiversity: is habitat heterogeneity the key? Trends Ecol Evol 18:182188

Brose U (2003) Regional diversity of temporary wetland carabid beetle communities: a matter of landscape features or cultivation intensity? Agric Ecosyst Environ 98:163-167

Cam E, Nichols JD, Hines JE, Sauer JR, Alpizar-Jara R, Flather CH (2002) Disentangling sampling and ecological explanations underlying species-area relationships. Ecology 83:1118-1130

Chust G, Pretus JL, Ducrot D, Bedos A, Deharveng L (2003) Response of soil fauna to landscape heterogeneity: determining optimal scales for biodiversity modeling. Conserv Biol 17:1712-1723

Chust G, Pretus JL, Ducrot D, Ventura D (2004) Scale dependency of insect assemblages in response to landscape pattern. Landsc Ecol 19:41-57

Cole L, Buckland SM, Bardgett RD (2005) Relating microarthropod community structure and diversity to soil fertility manipulations in temperate grassland. Soil Biol Biochem 37:1707-1717

Colwell RK (2005) EstimateS: statistical estimation of species richness and shared species from samples (statistical estimation software). RK Coldwell, University of Connecticut, Storrs, CT

Dauber J, Purtauf T, Allspach A, Frisch J, Voigtlander K, Wolters V (2005) Local vs. landscape controls on diversity: a test using surface-dwelling soil macroinvertebrates of differing mobility. Glob Ecol Biogeogr 14:213-221

Davies KF, Margules CR, Lawrence KF (2000) Which traits of species predict population declines in experimental forest fragments? Ecology 81:1450-1461

De Deyn GB, Raaijmakers CE, van Ruijven J, Berendse F, van der Putten WH (2004) Plant species identity and diversity effects on different trophic levels of nematodes in the soil food web. Oikos 106:576-586

Deharveng L (1996) Soil Collembola diversity, endemism, and reforestation: a case study in the Pyrenees (France). Conserv Biol 10:74-84

Didham RK, Hammond PM, Lawton JH, Eggleton P, Stork NE (1998a) Beetle species responses to tropical forest fragmentation. Ecol Monogr 68:295-323

Didham RK, Lawton JH, Hammond PM, Eggleton P (1998b) Trophic structure stability and extinction dynamics of beetles (Coleoptera) in tropical forest fragments. Philos Trans R Soc Lond B Biol Sci $353: 437-451$
Dunger W, Schulz HJ, Zimdars B (2002) Colonization behaviour of Collembola under different conditions of dispersal. Pedobiologia 46:316-327

Dunn RR (2004) Managing the tropical landscape: a comparison of the effects of logging and forest conversion to agriculture on ants, birds, and Lepidoptera. For Ecol Manage 191:215-224

Eggleton P, Bignell DE, Hauser S, Dibog L, Norgrove L, Madong B (2002) Termite diversity across an anthropogenic disturbance gradient in the humid forest zone of West Africa. Agric Ecosyst Environ 90:189-202

Eggleton P, Vanbergen AJ, Jones DT, Lambert MC, Rockett C, Hammond PM, Beccaloni J, Marriott D, Ross E, Giusti A (2005) Assemblages of soil macrofauna across a Scottish land-use intensification gradient: influences of habitat quality, heterogeneity and area. J Appl Ecol 42:1153-1164

Ellner SP, McCauley E, Kendall BE, Briggs CJ, Hosseini PR, Wood SN, Janssen A, Sabelis MW, Turchin P, Nisbet RM, Murdoch WW (2001) Habitat structure and population persistence in an experimental community. Nature 412:538-543

Ettema CH, Wardle DA (2002) Spatial soil ecology. Trends Ecol Evol 17:177-183

Fjellberg A (1998) The Collembola of Fennoscandia and Denmark. Brill, Leiden

Gillison AN, Jones DT, Susilo FX, Bignell DE (2003) Vegetation indicates diversity of soil macroinvertebrates: a case study with termites along a land-use intensification gradient in lowland Sumatra. Org Divers Evol 3:111-126

Hansen RA (2000) Effects of habitat complexity and composition on a diverse litter microarthropod assemblage. Ecology 81:1120-1132

Hansen RA, Coleman DC (1998) Litter complexity and compostion are determinants of the diversity and species composition of oribatid mites (Acari: Oribatida) in litter bags. Appl Soil Ecol 9:17-23

Hanski I (1999) Metapopulation ecology. Oxford University Press, New York

Hedlund K, Ohrn MS (2000) Tritrophic interactions in a soil community enhance decomposition rates. Oikos 88:585-591

Herrando S, Brotons L (2002) Forest bird diversity in Mediterranean areas affected by wildfires: a multi-scale approach. Ecography 25:161-172

Hooper DU, Bignell DE, Brown VK (2000) Interactions between above- and below-ground biodiversity in terrestrial ecosystems: patterns, mechanisms and feedbacks. Bioscience 50:1049-1061

Hopkin SP (1997) The biology of the Springtails. Oxford University Press, Oxford

Hopkin S (2000) A key to the springtails (Insecta: Collembola) of Britain and Ireland. Field Studies Council, Shrewsbury, UK

Hoyle M, Harborne AR (2005) Mixed effects of habitat fragmentation on species richness and community structure in a microarthropod microecosystem. Ecol Entomol 30:684-691

Ims RA, Leinaas HP, Coulson S (2004) Spatial and temporal variation in patch occupancy and population density in a model system of an arctic Collembola species assemblage. Oikos 105:89-100

Jones DT, Susilo FX, Bignell DE, Hardiwinoto S, Gillison AN, Eggleton P (2003) Termite assemblage collapse along a land-use intensification gradient in lowland central Sumatra, Indonesia. J Appl Ecol 40:380-391

Joschko M, Fox CA, Lentzsch P, Kiesel J, Hierold W, Kruck S, Timmer J (2006) Spatial analysis of earthworm biodiversity at the regional scale. Agric Ecosyst Environ 112:367-380

Lawton JH, Bignell DE, Bolton B, Bloemers GF, Eggleton P, Hammond PM, Hodda M, Holt RD, Larsen TB, Mawdsley NA, Stork NE, Srivastava DS, Watt AD (1998) Biodiversity inventories, indicator taxa and effects of habitat modification in tropical forest. Nature 391:72-76

MacArthur R, Wilson EO (1967) The theory of Island biogeography. Princeton University Press, Princeton, NJ 
Maraun M, Salamon JA, Schneider K, Schaefer M, Scheu S (2003) Oribatid mite and collembolan diversity, density and community structure in a moder beech forest (Fagus sylvatica): effects of mechanical perturbations. Soil Biol Biochem 35:1387-1394

Pearman PB (2002) The scale of community structure: habitat variation and avian guilds in tropical forest understory. Ecol Monogr 72:19-39

Ponge JF, Arpin P, Vannier G (1993) Collembolan response to experimental perturbations of litter supply in a temperate forest ecosystem. Eur J Soil Biol 29:141-153

Ponge JF, Gillet S, Dubs F, Fedoroff E, Haese L, Sousa JP, Lavelle P (2003) Collembolan communities as bioindicators of land use intensification. Soil Biol Biochem 35:813-826

Ponge JF, Dubs F, Gillet S, Sousa JP, Lavelle P (2006) Decreased biodiversity in soil springtail communities: the importance of dispersal and landuse history in heterogeneous landscapes. Soil Biol Biochem 38:1158-1161

Purtauf T, Dauber J, Wolters V (2005) The response of carabids to landscape simplification differs between trophic groups. Oecologia 142:458-464

Roland J, Taylor PD (1997) Insect parasitoid species respond to forest structure at different spatial scales. Nature 386:710-713

Salamon JA, Alphei J, Ruf A, Schaefer M, Scheu S, Schneider K, Suhrig A, Maraun M (2006) Transitory dynamic effects in the soil invertebrate community in a temperate deciduous forest: effects of resource quality. Soil Biol Biochem 38:209-221

Sims RW, Gerard BM (1999) Earthworms. Synopses of the British fauna (new series). Field Studies Council, Shrewsbury, UK

Sousa JP, Bolger T, da Gama MM, Lukkari T, Ponge JF, Simon C, Traser G, Vanbergen AJ, Brennan A, Dubs F, Ivitis E, Keating A, Stofer S, Watt AD (2006) Changes in Collembola richness and diversity along a gradient of land-use intensity: a pan European study. Pedobiologia 50:147-156

St John MG, Wall DH, Behan-Pelletier VM (2006) Does plant species co-occurrence influence soil mite diversity? Ecology 87:625-633

Stace C (1997) New flora of the British Isles. Cambridge University Press, Cambridge, UK

Steffan-Dewenter I, Munzenberg U, Burger C, Thies C, Tscharntke T (2002) Scale-dependent effects of landscape context on three pollinator guilds. Ecology 83:1421-1432

ter Braak CFJ, Śmilauer P (1998) CANOCO for Windows version 4. Centre for Biometry, Wageningen

Tews J, Brose U, Grimm V, Tielborger K, Wichmann MC, Schwager M, Jeltsch F (2004) Animal species diversity driven by habitat heterogeneity/diversity: the importance of keystone structures. J Biogeogr 31:79-92

Thies C, Steffan-Dewenter I, Tscharntke T (2003) Effects of landscape context on herbivory and parasitism at different spatial scales. Oikos 101:18-25

Tscharntke T, Steffan-Dewenter I, Kruess A, Thies C (2002) Contribution of small habitat fragments to conservation of insect communities of grassland-cropland landscapes. Ecol Appl 12:354-363

Vanbergen AJ, Woodcock BA, Watt AD, Niemela J (2005) Effect of land-use heterogeneity on carabid communities at the landscape scale. Ecography 28:3-16

Wardle DA, Barker GM, Yeates GW, Bonner KI, Ghani A (2001) Introduced browsing mammals in New Zealand natural forests: aboveground and belowground consequences. Ecol Monogr 71:587-614

Wardle DA, Yeates GW, Williamson W, Bonner KI (2003) The response of a three trophic level soil food web to the identity and diversity of plant species and functional groups. Oikos 102:45-56 